Animal Conservation,vol. 4, no.3, 2001, pp.239-249.

ISSN: $1367-9430$

doi:10.1017/S1367943001001287

http://journals.cambridge.org/action/home

http://journals.ohiolink.edu/ejc/pdf.cgi/Treydte Anna C.pdf?issn=13679430\&issue=v04i0003\&article=239 isotomsfao

(C) Cambridge University Press

\title{
In search of the optimal management strategy for Arabian oryx
}

\author{
Anna C. Treydte ${ }^{1}$, Joseph B. Williams ${ }^{1}$, Eric Bedin ${ }^{2}$, Stéphane Ostrowski ${ }^{2}$, Phillip J. \\ Seddon $^{2}$, Elizabeth A. Marschall ${ }^{1}$, Thomas A. Waite ${ }^{1}$ and Khairy Ismail ${ }^{2}$ \\ ${ }^{1}$ Department of Evolution, Ecology, and Organismal Biology, Ohio State University, ${ }^{2}$ National Wildlife Research \\ Center, National Commission for Wildlife Conservation and Development, Taif, Saudi Arabia
}

\begin{abstract}
Extirpated from the wild in 1972 by overhunting, Arabian oryx (Oryx leucoryx) were re-introduced in Saudi Arabia in March 1990; 17 oryx were released into Mahazat as-Sayd, a $2244 \mathrm{~km}^{2}$ fenced reserve in westcentral Arabia, which lies at the periphery of their historical home range. The population has increased to 346 animals. The National Commission for Wildlife Conservation and Development, and those that manage the herd, have recently asked, 'What is the optimal management strategy to assure long-term persistence of the species, given the absence of immigration and predation?' Food resources, determinants of rates of mortality and birth, covary with unpredictable rainfall in Mahazat as-Sayd. Using data-driven assumptions, we developed a computer model that evaluated the probability of extinction $\left(P_{e x}\right)$ under various management strategies: no intervention, removing a fixed number of animals each year, removing a fixed percentage of animals each year, and removing all individuals above a threshold. In addition, we explored the probability that oryx populations would decline below two thresholds, called the probability of quasi-extinction $\left(P_{q-e x}\right)$ under various management schemes. Our analyses suggested that, without intervention, the oryx population had a high $P_{e x}$. Removing $15 \%$ of the current population provided a low $P_{e x}$, but this method also produced high values for $P_{q-e x}$ and, as a by-product, wide fluctuations in population size $(N)$. Although it required an assessment of both $N$ and carrying capacity $(K)$, the most successful management plan consisted of removing all oryx above $70 \%$ of $K$. Adoption of this plan resulted in low $P_{e x}$, low $P_{q-e x}$, and smaller fluctuations in $N$. Our study may provide a useful model for evaluating management plans for a variety of threatened animal populations in desert ecosystems.
\end{abstract}

\section{INTRODUCTION}

Once found throughout the Arabian Peninsula, the Arabian oryx (Oryx leucoryx) was eradicated from the wild in 1972 by over-hunting and poaching (Henderson, 1974). Prior to extirpation, several captive-breeding programmes were initiated with the intent of re-establishing oryx into native habitats (Talbot, 1960; Stanley Price, 1989). The first reintroduction back into the wild occurred in 1982 on the Jiddat al-Harasis, a 25,000 $\mathrm{km}^{2}$ reserve in central Oman, now a World Heritage Site (Spalton, Lawrence \& Brend, 1999). In 1986, through the efforts of HRH Prince Saud Al Faisal and the staff of the National Wildlife Research Center (NWRC), a captivebreeding programme was initiated with the purpose of re-establishing this endangered species in Saudi Arabia. In March 1990, a founder population of 17 oryx was released into Mahazat asSayd, a 2,244 $\mathrm{km}^{2}$ fenced reserve in west-central Saudi Arabia (Ostrowski et al., 1998). With a few subsequent additions from the captive herd, and from natural births, the population increased significantly, and in May 2000 had reached about 346 individuals (Seddon \& Ismail, 2000). This herd represents the largest remaining natural population in the world, and, as a result, proper management is of concern to those interested in the preservation of this species.

Mahazat as-Sayd lies in the Arabian desert, where primary production is low, rainfall is 
unpredictable and patchily distributed, and ambient air temperatures $\left(T_{a}\right)$ often exceed $45^{\circ} \mathrm{C}$ (Corp, Spalton \& Gorman, 1998). One might not expect a large ungulate (80-100 kg) to occupy such an austere habitat because it is thought that ungulates have high water requirements (Nagy \& Peterson, 1989). However, Arabian oryx can survive indefinitely in this area without drinking, as long as they can find grasses and herbs with sufficient moisture content (Tear, Mosley \& Ables, 1997; pers. obs.). Rainfall and high $T_{a}$ s affect grass resources available to oryx, and, population dynamics of the herd (Thalen, 1979; Bell, 1985). Fluctuations in rainfall and $T_{a}$ may influence survival rates and birth rates, both of which affect population growth (Gaillard et al., 2000). Because the oryx population has increased significantly over the past decade, questions about future management policies have arisen. Specifically, one would like to know the optimal management strategy that assures long-term persistence of the species given that immigration and predation are absent.

A fundamental goal of population biologists is to elucidate the complex array of mechanisms and their, often non-linear, interactions that limit the number of animals in a given area (Hastings, 1997; May, 1999). In attempting to understand these mechanisms and interactions, researchers have often relied on mathematical models to acquire insights (Connell, 1983; Mangel \& Clark, 1988; Harrison, 1995; Hastings, 1997). Although a predictive understanding of long-term changes in population numbers has yet to emerge (May, 1999), many useful ideas have been developed which recently have been applied to problems in conservation biology (Starfield \& Bleloch, 1991), especially in the assessment of the risk of extinction to small populations of endangered species (Burgman, Ferson \& Akcakaya, 1993; Milner-Gulland, 1997; Bustamante, 1998).

The purpose of this study was to evaluate alternative management strategies for the oryx population in Mahazat as-Sayd, to identify an optimal plan that yielded the lowest probability of extinction $\left(P_{e x}\right)$, and to identify population parameters that need to be more closely monitored in the future. In addition, we examined the probability that populations would decline below various quasi-extinction thresholds, $P_{q-e x}$, under different management schemes. A by-product of this latter endeavour should be population stability, which is important because catastrophic mortality events cause alarm, though such occurrences may or may not be associated with high extinction probabilities. Although our efforts were directed towards a single population of ungulates in Arabia, the results should provide insights into possible management strategies for other populations of endangered herbivores in desert environments, especially those that are predator-free and confined to reserves.

\section{THE MODEL AND ITS UNDERLYING ASSUMPTIONS}

\section{Overview of the model}

We developed a model that established 100 virtual oryx populations and followed the trajectory of each population at discrete time steps of 1 year $(t)$, until a terminal time $(T)$ of 100 years (Treydte, 2000). The model applied data-driven functions for birth rate (b), survival (s) and carrying capacity $(K)$ to each population, all within the context of yearly environmental variations and density dependence. At each time step, the model provided a mean population size and variance for the 100 populations. We explored various management strategies such as no intervention, removing a fixed number of oryx each year, removing a fixed percentage of the population each year, and removing all animals above a threshold. 


\section{Climate}

In desert environments, rainfall, both timing and amount, and $T_{a}$ affect the available forage for ungulates (Caughley \& Gunn, 1993; Ghazanfar, 1997). The climate of Mahazat asSayd is characterized by hot summers and unpredictable rainfall. Mean $T_{a}$ ranged from $17^{\circ} \mathrm{C}$ in winter to $34^{\circ} \mathrm{C}$ in summer, but maximum $T_{a}$ in the summer often exceeded $45^{\circ} \mathrm{C}$. Rainfall was variable, ranging from $38 \mathrm{~mm}$ in 1999 to $253 \mathrm{~mm}$ in 1995 (Fig. 1). Mean annual rainfall from 1992 to 1999 was $96 \pm 70 \mathrm{~mm}$ (SD). Using data of rainfall and $T_{a}$ over the last decade, we examined the influence of these variables on the growth rate of the oryx population (Treydte, 2000).

\section{Calculation of an aridity index $(\mathbf{Q})$}

We combined measurements of $T_{a}$ and precipitation to calculate an aridity index (Q) for climatic conditions for each year (Emberger, 1955): $Q=100 \cdot R /(M+m) \bullet(M-m)$, where $R$ represents total annual rainfall, $M$ the mean maximum $T_{a}$ of the hottest month, and $m$ the mean minimum $T_{a}$ of the coldest month of each year. As for other desert regions, $Q$ closely mimicked patterns of rainfall. We scaled values of $Q$ relative to the year of highest rainfall, 1995, when $Q=$ 1.0 (16.5/16.5). $Q$ decreased as aridity increased.

\section{Population estimates}

We relied on empirical information on the oryx herd in Mahazat as-Sayd to generate relationships between demographic parameters and density, and between these parameters and

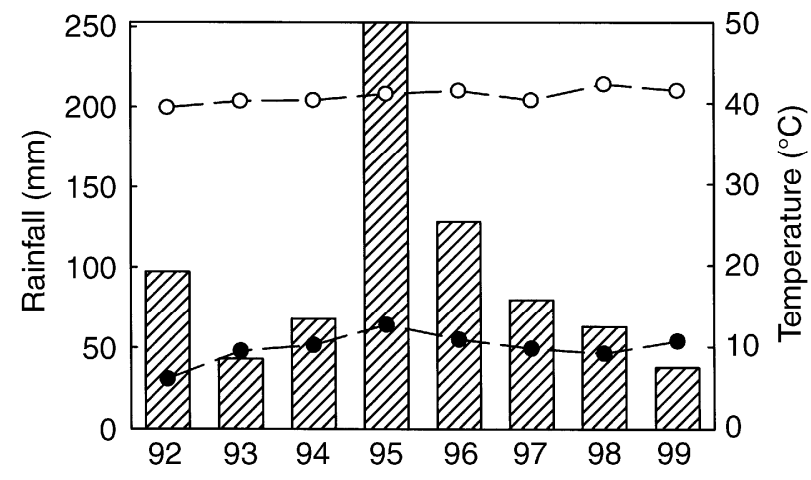

Fig. 1. Rainfall and air temperature in Mahazat as-Sayd from 1992 to 1999. Unfilled circles represent the mean maximum daily temperature; filled circles represent the mean minimum daily temperature. Bars show the annual rainfall in the reserve.

environment. This population has been monitored for the last decade, originally by counting all individuals each month and later, as the population increased, by estimating numbers of individuals using the Lincoln-Petersen Index, a method that requires that a subset of the population be marked (Pollock et al., 1990; Lancia, Nichols \& Pollock, 1992). At least 15\% of 
the oryx have been individually marked since the beginning of reintroduction. Births and deaths have been recorded for our marked population each month by rangers who patrol the reserve daily (Magin, Ismail \& Seddon, 1995; Ostrowski et al., 1998).

Since 1990 the oryx herd has increased from 17 to nearly 400 individuals (Fig. 2). Population growth was rapid until 1997 when it slowed, coincident with several years of poor rainfall. Because the herd is fenced, with no predators, immigration, emigration and predation were not considered.

\section{Carrying capacity}

The concept of carrying capacity, $K$, and its application to various ecosystems, has been the subject of debate for over a decade (Macnab, 1985; Cowling, 2000). In ungulate populations without predators, $K$ is reached when numbers of animals and food supply are in equilibrium, the maximum sustainable population size (Dasmann, 1981; Macnab, 1985). When applying this concept to field situations, problems arise because $K$ cannot be viewed as a fixed value, rather varying from year to year depending on, among other things, timing and amount of rainfall (Gaillard et al., 2000). Several studies suggest that vegetation biomass responds directly to the amount of rainfall in arid ecosystems (Beatley, 1974; Coe, Cumming \& Phillipson, 1976; Gulmon, Mooney \& Chu, 1983; Bowers, 1987). Below, we outline our approach for estimating $K$, adjusted annually depending on environmental conditions.

\section{Estimates of dry matter intake}

In Mahazat as-Sayd, Arabian oryx feed primarily on Stipagrostis spp., Panicum turgidum and Lasiurus scindicus during most of the year (Tear et al., 1997; E. Bedin \& S. Ostrowski, unpublished data). Determined using doubly labelled water (Speakman, 1997), the field metabolic rate of oryx during dry periods is 11,076 kJ/day and during periods after rain, 22,081 $\mathrm{kJ} / \mathrm{day}$. We have assumed that oryx work at the lower level of metabolism for 8 months of the year, and at the higher level for 4 months. Thus they have a weighted average energy expenditure of 14,744 kJ/day over the course of the year. Assuming the metabolizable energy content of their food is $10.9 \mathrm{~kJ} / \mathrm{g}$ dry matter (Nagy \& Knight, 1994), then adults consume $1.35 \mathrm{~kg} /$ day dry matter, or $493.7 \mathrm{~kg} /$ year. We assumed that juveniles consume $40 \%$ of adult intake, $197.5 \mathrm{~kg} / \mathrm{year}$. These estimates of dry matter intake are somewhat less than values for domestic steers of similar body mass, but nearly identical to those of sheep that weighed $80 \mathrm{~kg}$ (McDowell, 1985). 


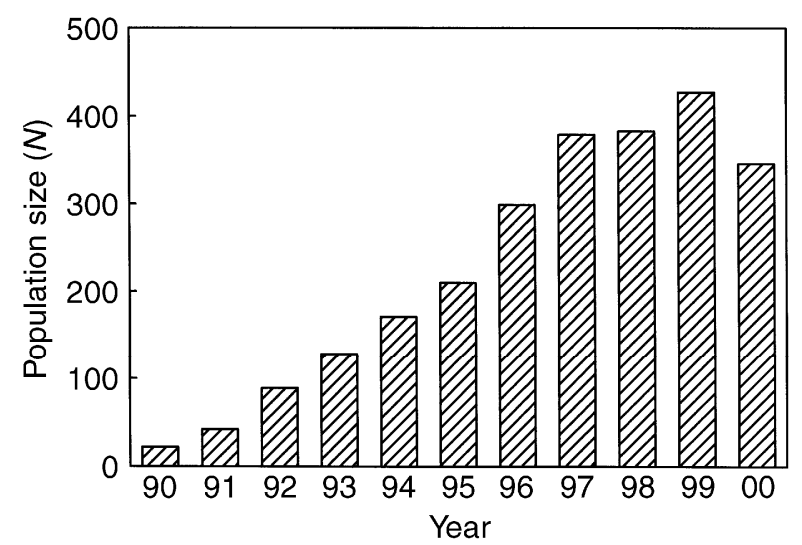

Fig. 2. Population size estimates for the Arabian oryx in Mahazat as-Sayd from 1990 to May 2000.

Estimation of total plant biomass during high-rainfall years

We estimated the maximum total dry matter available to oryx, given peak rainfall, by utilizing a SPOT satellite (Système Probatoire d'Observation de la Terre) photo taken of Mahazat as-Sayd in June 1995, the year in which $253 \mathrm{~mm}$ of rain fell. This map provided total vegetation cover of the reserve, subdivided into 17 colours, each representing an assemblage of plants that reflected light at unique wavelengths. We determined that 47,798 ha of Mahazat asSayd was covered by plants, $21 \%$ of the total area (225,000 ha) (Treydte, 2000).

To determine the total biomass available to oryx, we selected a point within each colour on the map, recorded its longitude and latitude, then, in Mahazat as-Sayd, established a $5 \times 5 \mathrm{~m}$ quadrat with the south-west corner as the chosen point, using a Global Positioning System. We next harvested all of the Stipagrostis spp., Panicum turgidum and Lasiurus scindicus plants within the quadrat and determined their dry mass (Treydte, 2000). Because we sampled plants in 1999, a year of poor rainfall, because we have not included all the plants eaten by oryx, and because we did not exclude grazers from our plots, we have undoubtedly underestimated total dry matter available in years of high rainfall, perhaps by $50 \%$ or more (Treydte, 2000). We arbitrarily increased our estimate of total dry mass by a factor of 1.75 to account for this difference. This provided us with an estimate of 373,903 kg dry matter available during years of high rainfall.

\section{Calculating maximum $K$}

We have no estimate of $K$ during drought years when $Q=0$. To arrive at an approximation, we regressed per capita growth rate $\left[\left(N_{t+1}-N_{t}\right) / N_{t}\right]$ against $N\left(r^{2}=0.60, F=\right.$ 11.9, $P<0.001$ ) (Fig. 3). The lower 95\% CI intersects the $x$-axis at 295 animals, which we assumed was $K_{\min }$ during years of poorest conditions. The estimated maximum number of oryx that Mahazat as-Sayd can support during a good year $\left(K_{\max }\right)$, however, could not be derived by 


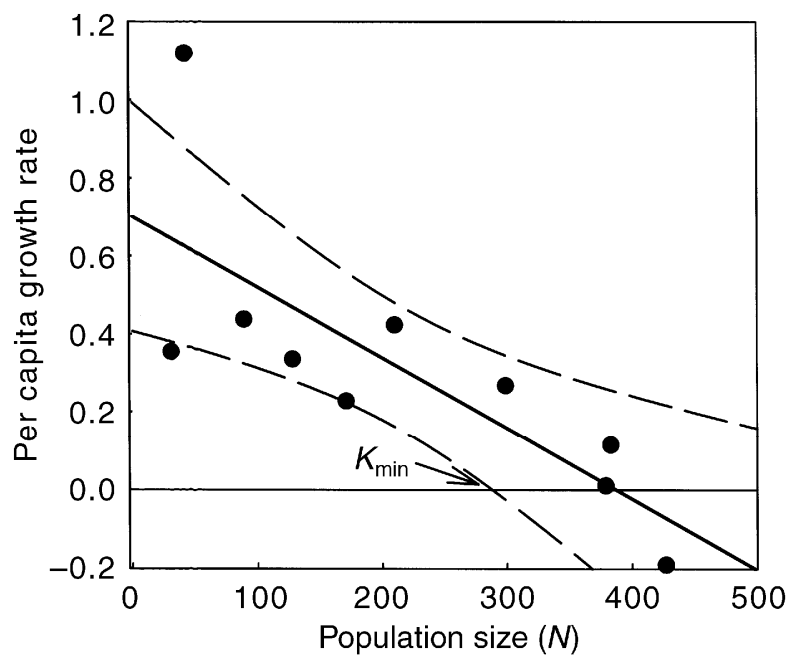

Fig. 3. Per capita growth rate for the oryx population in relation to population size $(N)$. The solid line represents a regression fitted to data points (filled circles) from 1990 to 1999. Dashed lines represent the upper and lower 95\% confidence interval. The lower limit of the $95 \% \mathrm{CI}$ crosses the $\mathrm{x}$-axis at $N=295$ animals, which we assume was $K_{\text {min }}$.

this method. To calculate $K_{\max }$, we weighted estimates of food intake by a ratio of $88 \%$ adult: $12 \%$ juveniles, and then divided the total biomass available by this average estimate to arrive at a value of 816 animals.

\section{Environment and $\mathrm{K}$}

We assumed a linear relationship between $Q$ and primary production for each population for each year, and that as primary production increased, so did $K$ (Noy-Meir, 1973; Coe et al., 1976). To derive a relationship between $K$ and $Q$, we first calculated values for $Q$ for each year, 1992 to 1999. This span of time includes a year with exceptionally high rainfall, 1995, and a year of drought conditions, 1999. For 1995, $Q=1.0$, whereas the lowest value of $Q$ was 0.14 for 1999. We calculated that $K_{\max }=816$ oryx when $Q=1$. We assumed that when $Q=0$, a point representative of the worst environmental conditions for which we have no data, $K_{\min }$ would be 295 animals. We used the line connecting these points to model $K$ as a function of $Q ; K=K_{\min }+$ $Q\left(K_{\max }-K_{\min }\right)$. We assumed a probability of $1 / 9$ that a population experienced a particular value of $Q$ in any given year. Our algorithm randomly selected a value of $Q$ for each population each year, then assigned a value for $K$ that corresponded to these environmental conditions for that population during that time step.

\section{Demography}

We divided the oryx population into four categories: adult females, adult males, juveniles between 1 and 2 years, and calves aged $<1$ year, and assigned birth and survival rates to each age class. We assumed that when juveniles became sexually mature adults, at the age of 2 years, $50 \%$ were males and 50\% were females. We also assumed that juveniles comprised $12 \%$ of each initial population based on average values over the last decade (Ostrowski et al., 1998). 
Stochasticity in demographic parameters

In the following sections, we develop mean values and predictive equations for demographic parameters for the oryx herd using data collected over the last decade. To simulate stochasticity in these parameters, an important consideration when predicting the probability of extinction $\left(P_{e x}\right)$ for small populations (Saether et al., 2000), we assumed that $b$ and $s$ were distributed normally with means and SD calculated from the data. Birth and survival rates in each simulation were drawn randomly from these normal distributions at each time step (Starfield \& Bleloch, 1991; Press et al., 1992).

\section{Birth rate}

Birth rates $(b)$, the number of births during the time period $(t)$ divided by the total number of mature females, were based on births in the marked subsample of females which have numbered from 10 to 49 individuals over the last decade (Seddon, 1999). We used several scenarios of birth rates in our model (Table 1).

\section{Birth rates and the Allee effect}

At low population densities $b$ was reduced, at medium densities it increased, and at high densities it declined again (Fig. 4(a)). We fit a quadratic model to the data; birth rate $(b)=0.43+$ $0.007(N)-0.00001(N)^{2}\left(r^{2}=0.92, F=38.4, P<0.001\right)$. The low $b$ at small $N$ could represent an Allee effect in which reproduction suffers because individuals have difficulty finding mates or because the normal social structure is disrupted (Allee, 1938; Courchamp, Clutton-Brock \& Grenfell, 1999; Stephens \& Sutherland, 1999). This finding could also have been the result of some founder effect that would not occur again should the population decline to low levels (Grant, 1998). We explored outcomes with an Allee effect included in our model (Table 1).

\section{Density dependence of birth rates}

We also explored extinction risk under the assumption that $b$ was constant up to the calculated $K$ for that population. We calculated an average $b$ value of $1.1 \pm 0.09$ births per female based on data from 1993 to 1996 (Fig. 2), when $b$ was not influenced by effects of either high or low density. In our first scenario, $b$ was held constant until the population reached $K$, then $b$ declined linearly to zero at $2 K$ (Fig. 4(b), Table 1 ). It could also be that $b$ is affected only after $K$ is exceeded by some unknown number of animals. To simulate this scenario, we assumed $b$ was constant until $N$ reached a value $30 \%$ above $K$, thereafter declining to zero at $2 K$ (Fig. 4 (b), Table 1). To guide our selection of an upper value, we assessed a 
(a)

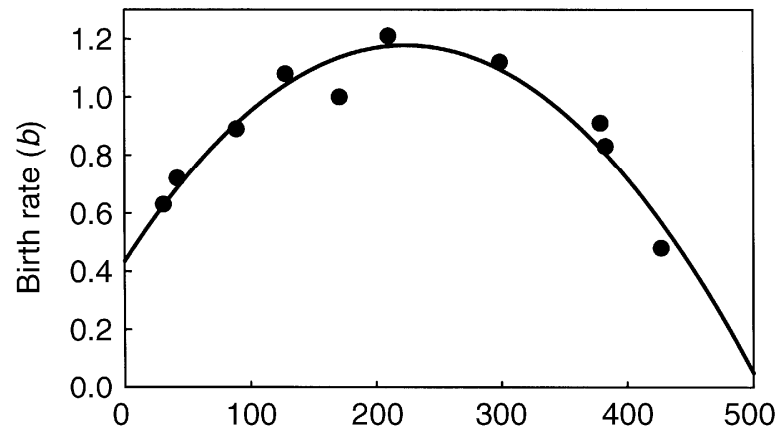

(b)

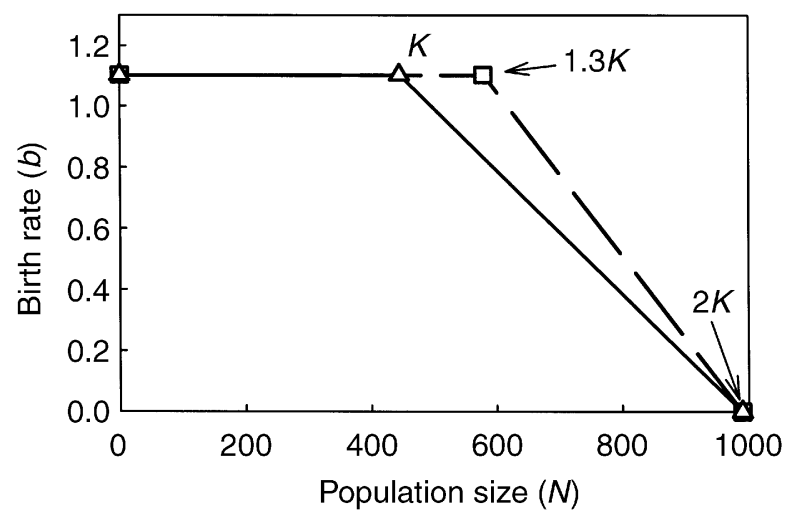

Fig. 4. (a) Birth rate (b) as a function of population size for oryx from 1990 to 1999. Filled circles represent actual data. Fig. 4(b) Birth rate $(b)$ of oryx calculated by taking an average value for the years 1993-96. Above $K$, solid line shows a linear decline in $b$ to $b=0$ at $N=2 K$. Dashed line shows a delayed response in a density dependent decline in $b$ after $1.3 \mathrm{~K}$ is reached. As an example of $K$ the median of our nine possible $K$-values is given.

Table 1. Combinations of birth rate and survival rate as tested in our model

\begin{tabular}{|c|c|c|}
\hline Birth rate $(b)$ & $\begin{array}{l}\text { Negat } \\
\text { rate }(\end{array}$ & $\begin{array}{l}\text { tive density dependence in survival } \\
\text { s) }\end{array}$ \\
\hline (1) Allee effect & $\begin{array}{l}\text { (a) } \\
\text { (b) }\end{array}$ & $\begin{array}{l}\text { negatively density dependent above } K \\
\text { with } s=0 \text { at } N=2 K \\
\text { negatively density dependent above } \\
1.3 K \text { with } s=0 \text { at } N=2 K\end{array}$ \\
\hline \multirow{2}{*}{$\begin{array}{l}\text { (2) negatively density } \\
\text { dependent above } K \\
\text { with } b=0 \text { at } N=2 K\end{array}$} & (a) & $\begin{array}{l}\text { negatively density dependent above } K \\
\text { with } s=0 \text { at } N=2 K\end{array}$ \\
\hline & (b) & $\begin{array}{l}\text { negatively density dependent above } \\
1.3 K \text { with } s=0 \text { at } N=2 K\end{array}$ \\
\hline \multirow[t]{2}{*}{$\begin{array}{l}\text { (3) negatively density } \\
\text { dependent above } \\
1.3 K \text { with } b=0 \text { at } N=\end{array}$} & $2 K$ & $\begin{array}{l}\text { negatively density dependent above } K \\
\text { with } s=0 \text { at } N=2 K\end{array}$ \\
\hline & (b) & $\begin{array}{l}\text { negatively density dependent above } \\
1.3 K \text { with } s=0 \text { at } N=2 K\end{array}$ \\
\hline
\end{tabular}

mean of 468 individuals \pm 1 SD (149.8) of $K$ for 9 years. Since the SD was about 30\% of mean 
$K$, we assumed that $b$ declined after $1.3 K$. The equation $b=2 b / 0.7-(b / 0.7 K) N$ yielded values for $b$ between $1.3 K$ and $2 K$.

Although Mahazat as-Sayd has not experienced a year with no rain, there is evidence from the population in Oman that during years when rainfall does not occur, birth rates of oryx decline (Spalton et al., 1999). We assumed that when $Q=0$, birth rates would be impacted when $N<K$. To derive an estimate of this reduced $b$, we regressed $b$ against $Q$ : birth rate $(b)=0.75+$ $0.52(Q)\left(r^{2}=0.41, F=4.1, P=0.09\right)$. We assigned a value to $b$ of 0.75 when $Q=0$ and when $N$ was $<K$.

\section{Survival rates}

Survival rates (s), the proportion of individuals that survive from one time step to the next, were relatively high for adult males and females, and for calves from 1993 to 1999 (Fig. 5). We did not have survival estimates for juveniles, an age class that has infrequently been individually marked. For juveniles, we assumed a value of $s$ equivalent to that of calves. However, we kept these categories separate in the model for heuristic purposes, and because juvenile mortality is probably different from that of calves (Gaillard, Festa-Bianchet \& Yoccoz, 1998; Marshall \& Spalton, 2000). In the future, if juvenile survival rates are measured, these parameters can be inserted into the model. We tested the relationship of $s$ versus $N$ for 1993 to 1999 and with data from 1993 excluded because the population was relatively small at this time (Fig. 2).

Intuitively, one might expect that survival decreases at high population densities (Clutton-Brock et al., 1992). When we regressed $s$ against $N$, we found a positive trend for males from 1993 to 1999, survival $(s)=0.61+0.0009(N)\left(r^{2}=0.59, F=7.2, P=0.04\right)$. Although the mechanism for this relationship remains obscure, it could be that when $N$ is small, males intensify their aggressive behaviour towards other males for access to females, thereby increasing mortality rates (see also Marshall \& Spalton, 2000). We assumed that $s$ was described by this equation up to an asymptote of 0.9 , the mean survival rate for males with the lowest datum excluded (Fig. 6(a)). Survival remained constant until $K$ was reached, and thereafter declined linearly to zero at $2 K$.

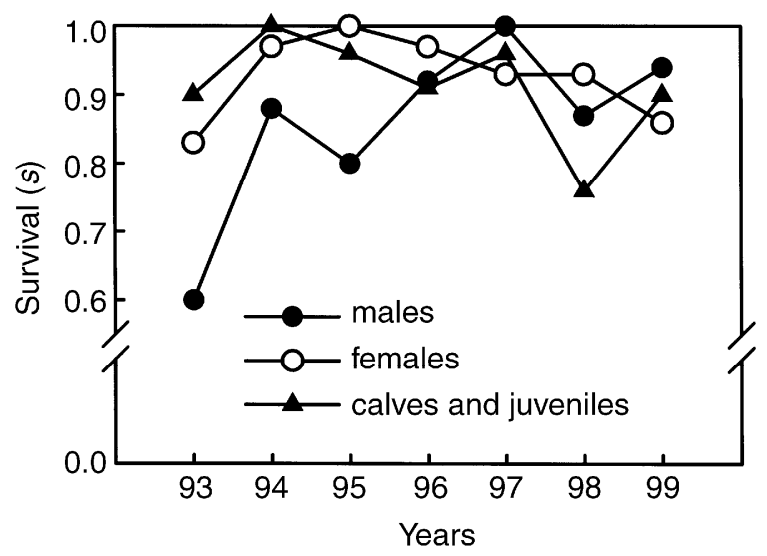


Fig. 5. Survival data for the Arabian oryx population in Mahazat as-Sayd from 1993 to 1999.
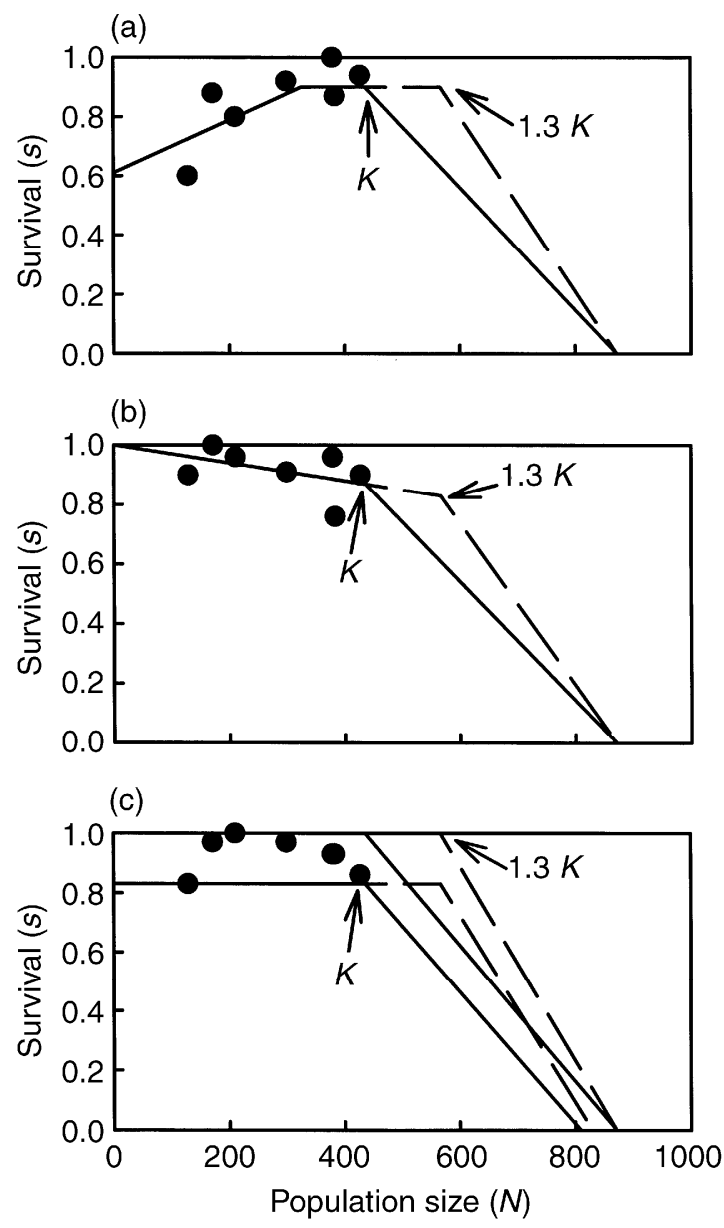

Fig. 6. (a) Male survival ( $s$ ) versus population size $(N)$ where $s$ was positively density dependent until an asymptote at $s=0.9$, the average value of $s$ from 1994-1999. After $K$ was reached, solid line shows $s$ declining linearly to $s=0$ at $N=2 K$. Dashed line represents a delayed decline in $s$ after $N$ exceeded $1.3 K$ to $s=0$ at $N=2 K$. Fig. 6(b) Calf and juvenile survival (s) versus $N$. Survival declined until $N=K$, then $s$ declined linearly to zero at $N=2 K$ (solid line). Dashed line shows a delayed decline in $s$ after $N$ exceeded $1.3 K$ to $s=0$ at $N=2 K$. Fig. 6(c) Female survival (s) versus $N$ also dependent on the aridity index $(Q)$. A randomly chosen value of $Q$ predicts $s$ (range within solid lines) newly every year. Population density additionally influences $s$ when $N>K$ with $s$ declining linearly to $s=0$ at $N=$ $2 K$. Range within dashed lines shows a delayed decline in $s$ after $N$ exceeded $1.3 K$ to $s=0$ at $N=2 K$. Black dots show data points from 1993 to 1999 for (a), (b) and (c).

Survival of large mammals sometimes remains high even at high population densities, owing to their ability to survive harsh periods by reducing energy expenditure through modification of their behaviour (Saether, 1997). To simulate a delayed effect of exceeding $K$ on $s$, we assumed that $s$ was constant up to $1.3 K$, and thereafter diminished to zero at $2 K$ (Table 1 , Fig. 6(a)).

Calves and juveniles showed a slight decrease in $s$ with increasing $N$ during 1993 to 1999: survival $(s)=1.0-0.0003(N)$ (Fig. $6(\mathrm{~b}) ; r^{2}=0.19, F=1.2, P=0.3$ ). We assumed that this equation described calf and juvenile survival up to $K$. We examined two possible 
relationships of $s$ versus $N$ above $K$. First, we assumed that $s$ decreased linearly from $K$ to $2 K$. Second, we assigned values to $s$ with our equation until $1.3 K$ was reached, then $s$ declined until $s$ $=0$ at $2 K$.

Even though we found no trends between $Q$ and calf or juvenile survival, there is some evidence that during extremely dry years, calf mortality increases (S. Ostrowski, pers. obs.). We assumed that, when $Q=0$, calf survival will fall by 50\%. For females, our calculations were complicated by the fact that $s$ was influenced both by $Q$, survival $(s)=0.87+0.15(Q)\left(r^{2}=0.54\right.$, $F=5.8, P=0.06$ ), and by density (Fig. 6(c)). A plot of survival versus density from 1994 to 1999 showed a significant negative trend, $(s)=1.07-0.0004(N)\left(r^{2}=0.69, F=8.9, P=0.04\right)$. For females, we calculated $s$ based on values of $Q$, if the population was below $K$. If $N$ was above $K$, we decreased the value of $s$ as given by our equation by the same proportion that $N$ was above $K$ with $s$ declining linearly to $s=0$ at $N=2 K$. For example, if $K=300$ and $N$ was calculated to be $360,20 \%$ above $K$, then we decremented values of $s$ as determined by $Q$, by $20 \%$. This is consistent with the notion that females tend to suffer more mortality from environmental exigency because of the added burden of providing nutrition both for fetal young and for calves (Stanley Price, 1989). Our second possibility was that $s$ was constant until $N$ reached $1.3 K$, thereafter declining to $2 K$ (Table 1 , Fig. 6(c)). Values of $s$ were calculated using the same procedure as for values of $b$ when we assumed a delay in density effects on this parameter.

\section{Probability of extinction $\left(P_{e x}\right)$ and quasi-extinction}

$\left(P_{q-e x}\right)$

The probability of extinction $\left(P_{e x}\right)$ was defined as the frequency with which our 100 initial populations fell to zero within 100 years. However, because small populations have a high $P_{e x}$, biologists often set thresholds of $N$ as lower boundaries below which more invasive protocols are implemented to preserve the population (Burgman et al., 1993; Spalton et al., 1999). Thus, we evaluated the probabilities of quasi-extinction $\left(P_{q-e x}\right)$, the term employed for these lower thresholds, as the frequency that our initial 100 populations fell below 100 and 150 animals. We arbitrarily selected 100 oryx as the lower quasi-extinction threshold (QET), and chose 150 animals as the other QET because it was about half of $K_{\min }$.

\section{RESULTS}

\section{Summary of test scenarios}

We evaluated four approaches to management of the oryx population: no intervention, removal of a fixed number of individuals each year, removal of a fixed percentage of $N$ each year, and removal of animals above a threshold, using various combinations of assumptions for $b$ and $s$ (Table 1). We refer to these combinations of assumptions by numbers and letters. For example, for scenario (1a) we explored outcomes when $b$ was described by a quadratic equation (Allee effect), and $s$ was considered negatively density dependent above $K$ with $s=0$ when $N=2 K$. 


\section{Probability of extinction with no intervention}

We explored $P_{e x}$ when no animals were removed allowing only density dependence and environmental stochasticity to influence numbers when $N$ exceeds $K$. Our results suggested that $P_{e x}$ ranged from 0.30 , when $b$ was given by our quadratic equation (Allee effect) and $s$ was negatively density dependent above $K$, to 0.92 when $b$ was constant up to $1.3 K$ and $s$ was impacted at densities above $1.3 \mathrm{~K}$ (Table 2). Mean population size steadily declined from about 400 animals down to about 150 animals after 100 years when no animals were removed (Fig. 7(a)). Variation about mean values was large, suggesting that populations often declined rapidly as a result of an overshoot of $K$, as influenced by $Q$. Thus, the model predicts that, unless a method of subtracting animals from the population is adopted, the oryx population in Mahazat as-Sayd has a high risk of extinction.

Under the scheme of no intervention, high values for $P_{e x}$ were obtained when we assumed that birth rates showed an Allee effect, indicating its potential importance in the demography of small populations of oryx (Table 2 ).

In all scenarios that assumed delayed density dependence in $s$ (Table 1), we observed that $P_{e x}$ was consistently higher than when we assumed an immediate decline in $s$ when $N>K$ (Table 2 ). This suggests that, if negative density dependence in $s$ is delayed, oryx populations are more likely to overshoot $K$ and collapse. Therefore they have a higher risk of extinction than if $s$ begins to decline immediately above $K$.

Table 2. Probability of extinction $\left(P_{e x}\right)$ for management strategies of no removal, removal of 2-12 oryx each year, removal of $5-15 \%$ of the oryx population each year, and probability of quasi-extinction $\left(P_{q-e x}\right)$ for the strategy of removing $15 \%$ of the population each year

\begin{tabular}{llllccl}
\hline & \multicolumn{7}{c}{ Test scenarios* } \\
\cline { 2 - 7 } Annual removal & $1 \mathrm{a}$ & $1 \mathrm{~b}$ & $2 \mathrm{a}$ & $2 \mathrm{~b}$ & $3 \mathrm{a}$ & $3 \mathrm{~b}$ \\
\hline No removal & 0.35 & 0.91 & 0.61 & 0.92 & 0.30 & 0.55 \\
Remove 2 oryx & 0.60 & 0.88 & 0.60 & 0.93 & 0.37 & 0.62 \\
Remove 8 oryx & 0.60 & 0.96 & 0.68 & 0.93 & 0.49 & 0.78 \\
Remove 12 oryx & 0.69 & 0.94 & 0.63 & 0.95 & 0.80 & 0.90 \\
Remove 5\% & 0.17 & 0.67 & 0.21 & 0.71 & 0.07 & 0.45 \\
Remove 10\% & 0.01 & 0.18 & 0.02 & 0.30 & 0.03 & 0.05 \\
Remove 15\% & 0.00 & 0.00 & 0.00 & 0.00 & 0.03 & 0.05 \\
& Probability of quasi-extinction & & & \\
QET $=100$ & 0.14 & 0.30 & 0.44 & 0.32 & 0.35 & 0.52 \\
QET $=150$ & 0.80 & 0.86 & 0.99 & 0.89 & 0.86 & 0.90 \\
\hline
\end{tabular}

*Test scenarios given in Table 1.

${ }^{\dagger} \mathrm{QET}=$ quasi-extinction threshold when $15 \%$ of $N$ removed each year. 

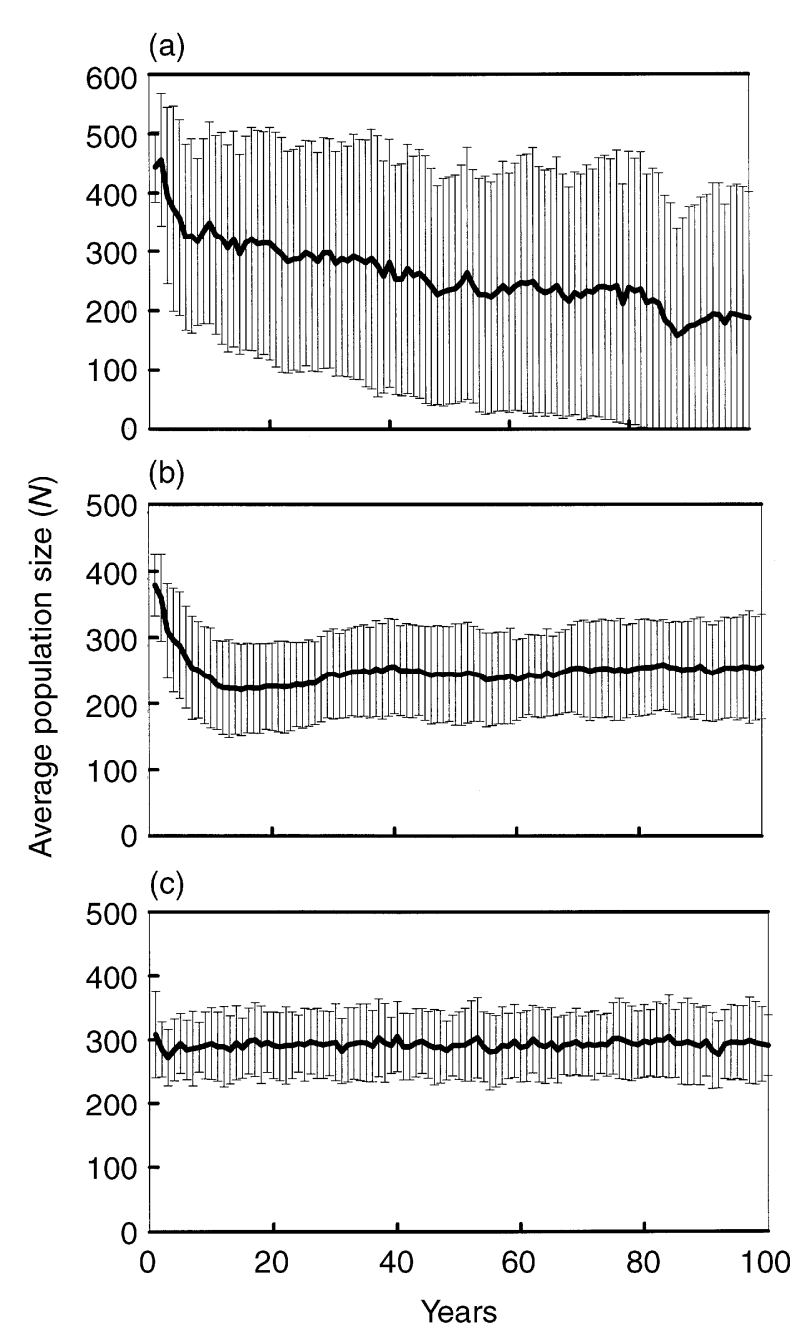

Fig. 7. (a) Mean population size ( $N \pm 1 \mathrm{SD}$ ) calculated for 100 iterations of $N$ over 100 years with no intervention. Fig. 7(b) Mean population size ( $N \pm 1 \mathrm{SD}$ ) when $15 \%$ of the population is removed each year. Fig. 7(c) Mean population size $(N \pm 1 \mathrm{SD}$ ) when all animals above $0.7 \mathrm{~K}$ are removed. In all scenarios we assumed that $b$ and $s$ were negatively density dependent above $K$.

\section{Removal of a fixed number of animals each year}

A simple intervention strategy, because it does not require an assessment of $N$, would be to remove an equal. Under all assumptions, this strategy resulted in higher $P_{e x}$ than if the population was unmanaged. Variances in $N$ were large, and the mean value for $N$ declined to $<100$ animals after 100 years when 12 animals were removed each year (data not shown). Removal of more than 12 animals per year resulted in higher values for $P_{e x}$. Because this strategy yielded unacceptable levels of $P_{e x}$, we explored other options.

\section{Removal of a fixed percentage of the current population each year}

For this management strategy, which relies on an assessment of $N$ each year, we removed a fixed percentage of each virtual population per year, equal numbers of males and females. We 
found that removing $15 \%$ of the current population provided the lowest $P_{e x}$ values (Table 2). Constant values of $b$ below $K$ and both assumptions about $s$ (Table 1) yielded $P_{e x}$ of zero when we removed $15 \%$ of the current $N$ each year.

The finding that removing $15 \%$ of $N$ lowered $P_{e x}$ to acceptable levels prompted us to explore the probability that $N$ might fall below two quasi-extinction thresholds, 100 and 150 individuals (Table 2). Under this strategy, $P_{q-e x}$ increased as the lower threshold increased, with most populations falling below 150 animals. Even though $P_{e x}$ was small when we removed $15 \%$ of the current $N$, populations tended to show wide fluctuations in numbers and the mean trajectory reached low values (Fig. 7(b)).

\section{Removal of all animals exceeding a percentage of $K$}

Removing all animals above a given percentage of $K$ is probably the most difficult strategy to implement owing to its requirement of assessing both $N$ and $K$ each year, but this was the most successful strategy at minimizing $P_{e x}$. For all assumptions of $b$ and $s, P_{e x}$ was zero when we removed all animals above $0.5 \mathrm{~K}$ and all animals above $0.7 \mathrm{~K}$ (Table 3 ). Removing animals above $0.9 \mathrm{~K}$ yielded a $P_{e x}$ that varied between 0.05 and 0.11 , whereas removing all animals above $K$ resulted in a $P_{e x}$ that varied from 0.09 to 0.22 .

Next we examined how this removal strategy affected the $P_{\text {q-ex }}$ for two thresholds, 100 and 150 animals (Table 4). Removing all animals above $0.7 \mathrm{~K}$ proved to be the most successful option at minimizing $P_{q-e x}$ for both thresholds. A $P_{q-e x}$ of 0.12 for QET $=150$ animals emphasizes that the oryx population in Mahazat as-Sayd will suffer some periods of decline in $N$ no matter which management plan is adopted, even though the $P_{e x}$ is at or near zero. Removal of oryx when $N$ exceeded $0.9 \mathrm{~K}$ or $K$ yielded large values for $P_{q-e x}$ for all QET, primarily because, at these levels, $N$ often exceeded $K$, which negatively affected $b$ and $s$, during the time step before removal took place.

We also explored mean population trajectories under the optimal management plan, removing oryx from the population when $N>0.7 \mathrm{~K}$ at the end of each time step. For all scenarios, mean population size was relatively stable and the variance small. We plot, as an example,

Table 3. Probability of extinction $\left(P_{e x}\right)$ for strategies of removing all animals above a proportion of carrying capacity $(K)$ when population size $(N)$ exceeded different percentages of $K$

\begin{tabular}{lcccccc}
\hline & \multicolumn{7}{c}{ Test scenarios* } \\
\cline { 2 - 7 } & $1 \mathrm{a}$ & $1 \mathrm{~b}$ & $2 \mathrm{a}$ & $2 \mathrm{~b}$ & $3 \mathrm{a}$ & $3 \mathrm{~b}$ \\
\hline Remove when & & & & & & \\
$N>0.5 K$ & 0.00 & 0.00 & 0.00 & 0.00 & 0.00 & 0.00 \\
$N>0.7 K$ & 0.00 & 0.00 & 0.00 & 0.00 & 0.00 & 0.00 \\
$N>0.9 K$ & 0.05 & 0.05 & 0.10 & 0.11 & 0.10 & 0.10 \\
$N>K$ & 0.11 & 0.09 & 0.20 & 0.21 & 0.20 & 0.22 \\
\hline
\end{tabular}

*Test scenarios given in Table 1 .

Table 4. Probability of quasi-extinction $\left(P_{q-e x}\right)$ for management strategies of removing all animals above a threshold, a proportion of the carrying capacity $(K)$, when the population size $(N)$ exceeded this threshold 


\begin{tabular}{|c|c|c|c|c|c|c|}
\hline & \multicolumn{6}{|c|}{ Test scenarios* } \\
\hline & $1 \mathrm{a}$ & $1 \mathrm{~b}$ & $2 a$ & $2 b$ & $3 a$ & $3 b$ \\
\hline $\begin{array}{l}\text { Remove when } N> \\
\text { QET }=100 \text { oryx } \\
\text { QET }=150 \text { oryx }\end{array}$ & $\begin{array}{r}0.5 K \\
0.01 \\
1.00\end{array}$ & $\begin{array}{l}0.01 \\
1.00\end{array}$ & $\begin{array}{l}0.01 \\
1.00\end{array}$ & $\begin{array}{l}0.01 \\
1.00\end{array}$ & $\begin{array}{l}0.01 \\
1.00\end{array}$ & $\begin{array}{l}0.01 \\
1.00\end{array}$ \\
\hline $\begin{array}{l}\text { Remove when } N> \\
\text { QET }=100 \text { oryx } \\
\text { QET }=150 \text { oryx }\end{array}$ & $\begin{array}{c}0.7 K \\
0.04 \\
0.12\end{array}$ & $\begin{array}{l}0.03 \\
0.05\end{array}$ & $\begin{array}{l}0.04 \\
0.12\end{array}$ & $\begin{array}{l}0.03 \\
0.06\end{array}$ & $\begin{array}{l}0.03 \\
0.07\end{array}$ & $\begin{array}{l}0.03 \\
0.04\end{array}$ \\
\hline $\begin{array}{l}\text { Remove when } N> \\
\text { QET }=100 \text { oryx } \\
\text { QET }=150 \text { oryx }\end{array}$ & $\begin{array}{c}0.9 K \\
0.24 \\
0.57\end{array}$ & $\begin{array}{l}0.23 \\
0.29\end{array}$ & $\begin{array}{l}0.24 \\
0.55\end{array}$ & $\begin{array}{l}0.21 \\
0.29\end{array}$ & $\begin{array}{l}0.16 \\
0.42\end{array}$ & $\begin{array}{l}0.08 \\
0.16\end{array}$ \\
\hline $\begin{array}{l}\text { Remove when } N> \\
\mathrm{QET}=100 \text { oryx } \\
\mathrm{QET}=150 \text { oryx }\end{array}$ & $\begin{array}{l}K \\
0.58 \\
0.89\end{array}$ & $\begin{array}{l}0.54 \\
0.66\end{array}$ & $\begin{array}{l}0.58 \\
0.88\end{array}$ & $\begin{array}{l}0.51 \\
0.63\end{array}$ & $\begin{array}{l}0.37 \\
0.76\end{array}$ & $\begin{array}{l}0.25 \\
0.42\end{array}$ \\
\hline
\end{tabular}

the mean population size when we assumed that $b$ was constant up to $K$ and that $s$ was density dependent above $K$ (conditions 2a, Table 1). Here mean population size was around 300 oryx with SD of $<60$ during the 100 years (Fig. 7(c)).

\section{DISCUSSION}

Our analyses suggest three salient points that not only apply to oryx in Mahazat as-Sayd, but also may have relevance to other populations of endangered ungulates in desert environments, especially those restricted to reserves. First, a management plan of no intervention, the one adopted for the oryx herd in Mahazat as-Sayd up till now, may yield a high $P_{e x}$ and large fluctuations in $N$. Among studies on herbivores, researchers disagree about the importance of weather, food limitation and predators in the process of population regulation (Messier \& Crete, 1985; Owen-Smith, 1990; McCullough, 1999). Few studies have been performed on demography of ungulates without predators, but, for reserves in many countries, predators have been reduced in number or completely eliminated. In the absence of predators, ungulates typically reach large $N$, with environmental stochasticity and density dependence being the main regulatory factors (Owen-Smith, 1990; Saether, 1997). Our model suggests that at high $N, P_{e x}$ is high, given the absence of influences like predation, immigration and emigration which may have played an important role during historical time. Dramatic declines in relatively large populations have been documented for Soay sheep living on an island, a result of overcrowding (Clutton-Brock et al., 1992; Grenfell et al., 1992). Using stochastic models to understand the extinction process, Ripa \& Lundberg (2000) argued that populations with high fluctuations in $N$ could collapse when at densities above carrying capacity, or when populations fall to low numbers, both of which would lead to extinction. Our model suggested that oryx face a hightened $P_{e x}$ if $N$ is either small or allowed to exceed $K$. Because of vagaries in desert environments (Aguiar \& Sala, 1999), an equilibrium between $N$ and $K$ as predicted by deterministic models is unlikely (Clark, 1976; Hastings, 1997), especially in a closed population such as oryx in Mahazat as-Sayd, and additional controlling influences will be required (Cowling, 2000).

Second, a management strategy of removing $15 \%$ of the current $N$ at the end of each year yielded a low $P_{e x}$, a marked improvement over no intervention or removal of a fixed number of 
animals each year. If an assessment of $K$ each year is impractical, because of the lack of personnel or financial resources, then this management plan may be preferred. However, adoption of this strategy may result in a varying $N$, causing the population size often to fall below 150 oryx. Hence, when implementing this plan, a certain level of mortality, especially during drought years, should be expected. Animals removed from Mahazat as-Sayd could be used as founders for other reintroductions, or added to other managed populations of oryx in an effort to maintain genetic diversity in these small populations (Bustamante, 1998; Vucetich \& Waite, 2000).

Third, the management strategy that minimized $P_{e x}$ and $P_{q-e x}$ was the removal of all individuals above a threshold of $0.7 \mathrm{~K}$ each year. Even though this strategy is the most labourintensive, requiring an annual assessment of $N$ and $K$, our analyses suggest that it provides the most assurance of long-term survival of oryx in Mahazat as-Sayd. This was also found in studies about the maximum sustainable yield in ungulate populations (Saether, Engen \& Lande, 1996), where maintenance of populations below $K$, around 0.5 to $0.75 \mathrm{~K}$ was the most successful (McCullough, 1979; Macnab, 1985).

For some populations of endangered species, an assessment of $N$ may be problematical. If considerable uncertainty exists in estimates of $N$, an alternative option is to remove only a proportion of the number of animals above the chosen threshold (Lande, Saether \& Engen, 1997). For example, under the plan of removing all animals above $0.7 K$, one might remove only $50 \%$ of the animals above this threshold if population size has probably been overestimated.

The strategy of removing animals above a threshold requires a reasonable estimate of $K$ each year, a difficult if not Sisyphean task. In our model we included stochasticity in $K$ because, in deserts, production is strongly influenced by rainfall which is highly variable (Caughley \& Gunn, 1993; Cowling, 2000). We recommend that attempts be made to correlate rainfall with primary production in Mahazat as-Sayd by constructing exclosure plots that are monitored annually, and by monitoring rain gauges throughout the reserve.

Our analyses pointed out some areas where managers of the oryx need to collect more data. In most studies of ungulates, annual survival rate varies between years within the range 0.4-0.8 (Owen-Smith, 1990; Saether, 1997). However, for our limited sample of oryx calves and juveniles, we found a relatively high survival rate, even in years of drought. Calf and juvenile mortality is an important factor because these animals consume either directly or indirectly available biomass, and yet are not recruited to the breeding population. Juvenile mortality seems to be significantly increased by high density of animals or by an unfavourable environment (Gaillard et al., 1998). In small populations like oryx, deviations in survival for juveniles could markedly affect the outcome of population viability analyses (Soulé, 1987). We recommend that more juveniles be marked in the oryx herd and their survival monitored.

Our data suggested the possibility that an Allee effect in birth rate operated in the oryx population. Since such a phenomenon can be critical for small populations (Dennis, 1989; Stephens \& Sutherland 1999), we recommend paying particular attention to this aspect of the demography of oryx. An Allee effect results in rapid decline in population growth at small population sizes, and, coupled to environmental and demographic stochasticity, leads to a high $P_{e x}$ (Courchamp et al., 1999). Furthermore, Marshall \& Spalton (2000) have recently suggested that, when $N$ is small, inbreeding depression may reduce survival for juvenile oryx, a phenomenon that we have not considered in our analyses.

An alternative management strategy that could be applied is sex-biased removal of animals. Removing females only could reduce reproductive potential, but it also requires 
knowledge of the number of females, of average harem size, and about density dependence in $b$ because an Allee effect in $b$ can lead to high values for $P_{e x}$ under this scenario. When we explored the desirability of this strategy, we found removal of $5 \%$ of the female population each year yielded similar results to removal of $15 \%$ of the entire population (data not shown). Removal of all females above $0.7 \mathrm{~K}$ or $0.5 \mathrm{~K}$ also provided low values for both $P_{e x}$ and $P_{q-e x}$. Such a management plan could reduce the numbers of animals being removed, for some an important issue (Burgman et al., 1993).

One might argue that the purpose of management is to minimize mortality and maximize birth rate, and feeding oryx during episodes of food shortage, such as droughts, would accomplish this goal. Additionally, because providing food will presumably reduce mortality, at least over the short term, this approach soothes our emotional discomfort about allowing animals to die; few conservationists enjoy watching animals perish. However, our analyses indicate that large population size does not guarantee a low $P_{e x}$, especially if variance in $N$ is large (Burgman et al., 1993; Ripa \& Lundberg, 2000). When supplemental food, and perhaps even water, is supplied, values for $s$ and $b$ will remain high, allowing the population to grow when density dependence would normally be controlling numbers. The result is that the oryx population will increase, eventually surpassing $K_{\max }$, when rainfall is at high levels $(Q=1)$. Large population size will undoubtedly have an adverse effect on grasses in the ecosystem through overgrazing (Cowling, 2000). What was invoked as a temporary remedial measure, supplemental feeding during periods of drought, now, because of high $N$, will probably become

a permanent fixture of the management process. If supplemental feeding is stopped when populations are high, our results indicate a high likelihood of a major decline in numbers in the future. In the short term, providing supplemental food to oryx may appear to be a viable solution, but over the long term, such a practice will not achieve population stability.

Population viability analysis (PVA) has become an important tool to predict $P_{e x}$ for endangered species (Soulé, 1987; Boyce, 1992; Morris et al., 1999), and has been used in several computer programs such as VORTEX and RAMAS in studies on a variety of species (Bustamante, 1998; Brook et al., 1999). Recently, techniques in adaptive management have been proposed where a feedback loop is established between model predictions and the observed response of the system. Management plans are annually adjusted on the basis of the fit between predictions and how the population has changed as a result of previous intervention (Walters, 1986; Williams, 1996). We see value in using adaptive management methods for conservation efforts, especially when environmental variation is large, as for example in deserts. Careful monitoring of the oryx population each year as management practices are applied will provide insights into their usefulness, and where appropriate, changes can be made to improve the outcome.

Even though we designed our analyses for application to the oryx population in Mahazat as-Sayd, our approach may also have utility for populations of other ungulates in semi-arid and arid environments. These landscapes are increasing, primarily as a result of global warming (Hughes, 2000), and therefore studies on ungulates that live in these habitats will gain increasing importance in the future (Caughley \& Gunn, 1993; Cowling, 2000).

\section{Acknowledgements}

We wish to express our appreciation to the National Commission for Wildlife Conservation and Development, Riyadh, and to the National Wildlife Research Center, Taif. In particular, we thank HRH Saud Al Faisal who has promoted wildlife protection in Saudi Arabia. Dr A. Abuzinada, Mr A. Khoja and Mr P. Paillat provided logistical 
support and encouragement throughout the study. We thank the rangers of Mahazat as-Sayd who provided warm hospitality on all occasions. P. Doherty, B. Kendall, J. Hines and M. Runge and the staff of the USGS Patuxent Wildlife Research Center kindly provided a stimulating atmosphere for A.C.T. during a portion of the development of the model. Funding for this project was received from the National Wildlife Research Center, Taif, Saudi Arabia, and from the Columbus Zoo, Columbus, OH. Part of this work was submitted by A.C.T. in partial fulfilment of the requirements for a Masters Degree at Ohio State University.

\section{REFERENCES}

Aguiar, M. R. \& Sala, O. E. (1999). Patch structure, dynamics and implications for the functioning of arid ecosystems. Trends Ecol. Evol. 14: 273-277.

Allee, W. C. (1938). The social life of animals. New York: W. W. Norton \& Co.

Beatley, J. C. (1974). Phenological events and their environmental triggers on Mojave Desert ecosystems. Ecology 55: 856-863.

Bell, R. H. V. (1985). Carrying capacity and offtake quotas. In Conservation and wildlife management in Africa. Bell, R. H. V. \& McShane-Caluzi, E. (Eds). Proceedings of a workshop held at Kasungu National Park, Malawi. Washington DC: U.S. Peace Corps.

Bowers, M. A. (1987). Precipitation and the relative abundance of desert winter annuals; a 6-year study in the northern Mojave Desert. J. Arid Environ. 21: 1-11.

Boyce, M. S. (1992). Population viability analysis. Annu. Rev. Ecol. Syst. 23: 481-508.

Brook, W. B., Cannon, J. R., Lacy, R. C., Mirande, C. \& Frankham, R. (1999). Comparison of the population viability analysis packages GAPPS, INMAT, RAMAS and VORTEX for the whooping crane (Gus americana). Anim. Conserv. 2: 23-31.

Burgman, M. A., Ferson, S. \& Akcakaya, H. R. (1993). Risk assessment in conservation biology. Population and Community Biology Series 12. London: Chapman \& Hall.

Bustamante, J. (1998). Use of simulation models to plan species reintroductions: the case of the bearded vulture in southern Spain. Anim. Conserv. 1: 229-238.

Caughley, G. \& Gunn, A. (1993). Dynamics of large herbivores in deserts: kangaroos and caribou. Oikos 67: 47-55.

Clark, C. (1976). Mathematical bioeconomics: the optimal management of renewable resources. New York: J. Wiley \& Sons.

Clutton-Brock, T. H., Price, O. F., Albon, S. D. \& Jewell, P. A. (1992). Early development and population fluctuations in Soay sheep. J. Anim. Ecol. 61: 381-396.

Coe, M. J., Cumming, D. H. \& Phillipson, J. (1976). Biomass and production of large African herbivores in relation to rainfall and primary production. Oecologia 22: 341-354.

Connell, J. H. (1983). On the prevalence and relative importance of interspecific competition. Am. Nat. 122: 661696.

Corp, N., Spalton, A. \& Gorman, M. L. (1998). The influence of rainfall on range in desert ungulates: the Arabian oryx (oryx leu-coryx) in the Sultanate of Oman. J. Zool. 246: 369-377.

Courchamp, F., Clutton-Brock, T. \& Grenfell, B. (1999). Inverse density dependence and the Allee effect. Trends Ecol. Evol. 14: 405-410.

Cowling, R. M. (2000). Challenges to the 'new' rangeland science. Trends Ecol. Evol. 15: 303-304.

Dasmann, R. F. (1981). Wildlife biology (2nd edn). New York: J. Wiley \& Sons.

Dennis, B. (1989). Allee effects: population growth, critical density, and the chance of extinction. Natural Resource Modeling 3: 481-538.

Emberger, L. (1955). 'Afrique du nord-ouest'. In Plant ecology: review of research: 219-249. Arid Zone Research 6. UNESCO: Paris.

Gaillard, J.-M., Festa-Bianchet, M. \& Yoccoz, N. G. (1998). Population dynamics of large herbivores: variable recruitment with constant adult survival. Trends Ecol. Evol. 13: 58-63.

Gaillard, J.-M., Festa-Bianchet, M., Yoccoz, N. G, Loison, A. \& Toïgo, C. (2000). Temporal variation in fitness components and population dynamics of large herbivores. Annu. Rev. Ecol. Syst. 31: 367-393.

Ghazanfar, S. A. (1997). The phenology of desert plants: a 3-year study in a gravel desert wadi in northern Oman. $J$. Arid Environ. 35: 407-417.

Grant, P. R. (1998). Evolution on islands. New York: Oxford University Press.

Grenfell, B. T., Price, O. F., Albon, S. D. \& Clutton-Brock, T. H. (1992). Overcompensation and population cycles in an ungulate. Nature 355: 823-826. 
Gulmon, S. L., Mooney, H. A. \& Chu, C. C. (1983). Phenology and resource use in the co-occurring grassland annuals. Oecologia 58: 33-42.

Harrison, G. W. (1995). Comparing predator-prey models to Luckinbill's experiment with Didinium and Paramecium. Ecology 76: 357-374.

Hastings, A. (1997). Population biology: concepts and models. New York: Springer Verlag.

Henderson, D. S. (1974). Were they the last Arabian oryx? Oryx 12: 347-350.

Hughes, L. (2000). Biological consequences of global warming: is the signal already apparent? Trends Ecol. Evol. 15: 56-61.

Lancia, R. A., Nichols, J. D. \& Pollock, K. H. (1992). Estimating the number of animals in wildlife populations. Ecol.

Monog. 62: 67-118.

Lande, R., Saether, B. E. \& Engen, S. (1997). Threshold harvesting for sustainability of fluctuating resources. Ecology 78: 1341-1350.

Macnab, J. (1985). Carrying capacity and related slippery shibboleths. Wildl. Soc. Bull. 13: 403-410.

Magin, C., Ismail, K. \& Seddon, P. (1995). Mahazat Ungulate Census, May 1995. Unpublished Report. National Wildlife Research Center, Taif, Saudi Arabia.

Mangel, M. \& Clark, C.W. (1988). Dynamic modelling in behavioral ecology. Princeton, NJ: Princeton University Press.

Marshall, T. C. \& Spalton, J. A. (2000). Simultaneous inbreeding and outbreeding depression in reintroduced Arabian oryx. Anim. Conserv. 3: 241-248.

May, R. (1999). Unanswered questions in ecology. Proc. R. Soc. Lond. ser. B 354: 1951-1959.

McCullough, D. R. (1979). The George Reserve deer herd: population ecology of a K-selected species. Ann Arbor: University of Michigan Press.

McCullough, D. R. (1999). Density dependence and life history strategies of ungulates. J. Mammal. 80: 1130-1146.

McDowell, L. R. (1985). Nutrition of grazing ruminants in warm climates. Orlando, FL: Academic Press Inc., Harcourt Brace Jovanovich.

Messier, F. \& Crete, M. (1985). Moose-wolf dynamics and the natural regulation of moose populations. Oecologia 65: 503-512.

Milner-Gulland, E. J. (1997). A stochastic dynamic programming model for the management of the Saiga antelope. Ecol. Applic. 7: 130-142.

Morris, W., Doak, D., Groom, M., Kareiva, P., Fieberg, J., Gerber, L., Murphy, P. \& Thomson, D. (1999). A practical handbook for population viability analysis. CA: The Nature Conservancy, University of California Press.

Nagy, K. A. \& Knight, M. H. (1994). Energy, water, and food use by springbok antelope (antidorcas marsupialis) in the Kalahari desert. J. Mammal. 75: 860-872.

Nagy, K. A. \& Peterson, C. C. (1989). Scaling of water flux rate in animals. Berkeley, CA: University of California Press.

Noy-Meir, I. (1973). Desert ecosystems: environment and producers. Annu. Rev. Ecol. Syst. 4: 25-41.

Ostrowski, S., Bedin, E., Lenain, D. M. \& Abuzinada, A. H. (1998). Ten years of oryx conservation breeding in Saudi Arabia - achievements and regional perspectives. Oryx 32: 209-222.

Owen-Smith, N. (1990). Demography of a large herbivore, the

greater kudu Tragelaphus strepsiceros, in relation to rainfall. J. Anim. Ecol. 59: 893-913.

Pollock, K. H., Nichols, J. D., Brownie, C. \& Hines, J. E. (1990). Statistical inference for capture-recapture experiments. Wildl. Monogr. 107: 1-97.

Press, W., Teukolsky, S. A., Vetterling, W. T. \& Flannery, B. P. (1992). Numerical recipes in C: the art of scientific computing. EXXON Research and Engineering Company. New York: Cambridge University Press.

Ripa, J. \& Lundberg, P. (2000). The route to extinction in variable environments. Oikos 90: 89-96.

Saether, B. E. (1997). Environmental stochasticity and population dynamics of large herbivores: a search for mechanisms. Trends Ecol. Evol. 12: 143-149.

Saether, B. E., Engen, S. \& Lande, R. (1996). Density-dependence and optimal harvesting of fluctuating populations. Oikos 76: 40-46.

Saether, B. E., Engen, S., Lande, R., Arcese, P. \& Smith, J. N. M. (2000). Estimating the time to extinction in an island population of song sparrows. Proc. R. Soc. Lond. ser. B 267: 621-626.

Seddon, P. (1999). Mahazat as-Sayd ungulate survey, June 1999. Unpublished Report. National Wildlife Research Center, Taif, Saudi Arabia.

Seddon, P. \& Ismail, K. (2000). Mahazat as-Sayd ungulate survey, May 2000. Unpublished Report. National 
Wildlife Research Center, Taif, Saudi Arabia.

Soulé, M. E. (1987). Viable populations for conservation. Cambridge: Cambridge University Press.

Spalton, J. A., Lawrence, M. W. \& Brend, S. A. (1999). Arabian oryx reintroduction in Oman: successes and setbacks. Oryx 33: 168-175.

Speakman, J. (1997). Doubly labelled water. London: Chapman \& Hall.

Stanley Price, M. R. (1989). Animal reintroductions: the Arabian oryx in Oman. Cambridge: Cambridge University Press.

Starfield, A. M. \& Bleloch, A. L. (1991). Building models for conservation and wildlife management. New York: Macmillan.

Stephens, P. A. \& Sutherland, W. J. (1999). Consequences of Allee effects for behavior, ecology and conservation. Trends Ecol. Evol. 14: 401-405.

Talbot, L. M. (1960). A look at threatened species. Oryx 5: 240-247.

Tear, T. H., Mosley, J. C. \& Ables, E. D. (1997). Landscape-scale foraging decisions by reintroduced Arabian oryx. J. Wildl. Mgmt. 61: 1142-1153.

Thalen, D. C. P. (1979). Ecology and utilization of desert shrub roughlands in Iraq. The Hague: W. Junk.

Treydte, A. C. (2000). In search of the optimal management strategy for Arabian oryx (Oryx leucoryx) in Mahazat as-Sayd, Saudi Arabia. Unpublished Masters thesis, Ohio State University, Columbus, OH.

Vucetich, J. A. \& Waite, T. A. (2000). Is one migrant per generation sufficient for the genetic management of fluctuating populations? Anim. Conserv. 3: 261-266.

Walters, C. J. (1986). Adaptive management of renewable resources. New York: MacMillan.

Williams, B. K. (1996). Adaptive optimization and the harvest of biological populations. Mathematical Biosciences 136: $1-20$.

Williams, J. B., Ostrowski, S., Bedin, E. \& Ismail, K. (In Press). Field metabolism and water flux of free-living Arabian oryx. J. Expt. Biology. 